\title{
The risk of malignancy and its incidence in early rheumatoid arthritis patients treated with biologic DMARDs
}

\author{
Soo-Kyung Cho ${ }^{1,2}$, Jiyoung Lee ${ }^{2}$, Minkyung Han², Sang-Cheol Bae ${ }^{1,2}$ and Yoon-Kyoung Sung 1,2*
}

\begin{abstract}
Background: Treatment with disease-modifying anti-rheumatic drugs (DMARDs) has raised concerns about the risk of malignancies in rheumatoid arthritis (RA) patients. However, the association between biologic DMARDs (bDMARDs) and malignancy in previous reports remains controversial. Therefore we aimed to estimate the incidence of malignancy in early RA patients and to evaluate the relative risk of malignancy with use of bDMARDs.

Methods: A retrospective cohort of incident RA patients was established using the Korean National Claims Database. Among a total of 14,081 RA patients identified, 1684 patients with a history of malignancy were excluded. We calculated the incidence rate of overall and individual malignancies. The standardized incidence ratio (SIR) of malignancies in bDMARD users was compared to that in nonusers. Multivariable logistic regression analysis was used to evaluate the impact of bDMARDs on the development of malignancies in early RA patients.

Results: A total of 12,397 early RA patients without a history of malignancy were enrolled. During 41,599 person-years (PY) of follow-up, 725 malignancies developed in 561 patients (174.3/10,000 PY) and 21 hematologic malignancies developed (5.0/10,000 PY). Patients treated with bDMARDs had a significantly lower incidence of overall malignancy compared to those not treated with bDMARDs (SIR 0.45 (95\% Cl 0.28-0.70)). However, this relationship was not significant with regard to hematologic malignancies (SIR 2.65 (95\% Cl 0.55-7.76)). On multivariable analysis, bDMARD use was a protective factor against the development of overall malignancy (odds ratio 0.42 ( $95 \% \mathrm{Cl}$ $0.25-0.73)$ ). However, bDMARD use had no significant protective effect against the development of hematologic malignancies (odds ratio 1.69 (95\% Cl 0.38-7.59)).
\end{abstract}

Conclusions: In early RA patients, bDMARD use decreases the overall risk of developing malignancies; however, it does not affect the risk of developing hematologic malignancies.

Keywords: Rheumatoid arthritis, Malignancies, Disease-modifying anti-rheumatic drugs, Biologic DMARDs

\section{Background}

Patients with rheumatoid arthritis (RA) are at increased risk of developing certain malignancies, including lymphoma, leukemia, and lung cancer [1-3]. This predisposition for malignancy is attributed to the immune dysregulation and/or chronic inflammation in RA, which increases cell proliferation, mutagenesis, oncogene activation, and angiogenesis [4]. Moreover, the long-term use of disease-modifying

\footnotetext{
* Correspondence: sungyk@hanyang.ac.kr

${ }^{1}$ Hanyang University Hospital for Rheumatic Diseases, 222-1 wangsimni-ro, Seongdong-gu, Seoul 04763, South Korea

${ }^{2}$ Clinical Research Center for Rheumatoid Arthritis (CRCRA), 222

wangsimni-ro, Seongdong-gu, Seoul 04763, South Korea
}

anti-rheumatic drugs (DMARDs), including methotrexate (MTX) and tacrolimus, is thought to increase risk of hematologic malignancies $[5,6]$. Recently, biologic DMARDs (bDMARDs) have become effective treatment options for RA patients with an inadequate response to MTX [7-9]. However, there are also concerns regarding malignancy with the use of these biologic agents given their target-specific inhibition of the immune system. Among various bDMARDs, concern is greatest with anti-tumor necrosis factor (anti-TNF) therapies, given the established role of TNF in tumor progression and surveillance [10]. 
A recent meta-analysis of randomized trials found that treatment with TNF inhibitors was associated with a 2-3.3-fold elevated risk of malignancy compared to non-TNF inhibitor therapies [11, 12]. However, other meta-analyses and observational studies have not identified a substantial increased risk of overall malignancies with TNF inhibitor use [13-15]. There are few studies that address cancer risk with the use of other (non-TNF inhibitor) bDMARDs. The only such studies that have been published are relatively short-term randomized trials that address the cancer risks of abatacept [16], tocilizumab [17], and rituximab [18] in RA. Also, recent postmarketing surveillance found that treatment with tocilizumab did not increase the risk of malignancy in RA patients [19].

Observational registry-based data also suggest that TNF inhibitors do not increase the risk of malignancy in patients with RA [20]. Furthermore, recent reports have suggested that TNF inhibitors actually decrease the risk of malignancies, with the exception of hematologic malignancies [21, 22]. Therefore, the association between bDMARDs and malignancy remains controversial [23]. It is also difficult to assess the influence of bDMARDs on malignancy development in patients with established RA because of the potential confounding influences of conventional DMARDs, long-term disease duration, or individual biases such as malignancy history.

Therefore, we aimed to determine the incidence of malignancies in newly diagnosed RA patients, and to evaluate the impact of bDMARDs on malignancy development.

\section{Methods}

\section{Data source}

An inception cohort of early RA patients was built based on the Health Insurance Review and Assessment (HIRA) database of South Korea. All people in South Korea are eligible for coverage under the National Health Insurance Program. Therefore, a total number of 47 million people, or over $96.3 \%$ of the total population, were included in the HIRA database [24]. This database contains individual beneficiary information, as well as healthcare service information including diagnosis, procedures, prescriptions, and tests. The HIRA Research Ethics Committee of South Korea approved this study protocol (NSCR-2014-3).

\section{Study population and outcomes Study population}

Patients with RA were identified using the diagnostic code for RA and records of prescriptions for any DMARDs. This RA definition was established according to our validated operational definition of RA in the HIRA database [25]. An inception cohort of incident RA patients was constructed containing patients who were identified as RA patients in 2010, were disease-free for 1 year prior to the index date, and received continuous treatment for $>3$ years from the index date onward. The index date was defined by the initiation of the first DMARD in 2010. Patients were observed until the development of a malignancy or until the end of the study period (in December 2013), whichever came first. A total of 14,081 early RA patients were identified. Patients with a history of malignancy $(n=1684)$ for at least 12 months prior to the index date were excluded (Fig. 1).

\section{Definition of malignancy}

The development of malignancy was defined as the appearance of the respective ICD-10 code between the index date and the last date of observation [26] (Additional file 1: Table S1). Malignancies were divided according to the involved systemic organs.

\section{Study design \\ Retrospective cohort study}

The incidence rate (IR) of malignancy was calculated for early RA patients without a history of malignancy in 2010. As described previously, patients were followed until the development of malignancy or until the last observational date. Therefore, patients without malignancy development were followed for 3-4 years. Patients were divided into two groups according to bDMARD exposure during the observational period: bDMARD everusers and bDMARD nonusers. Patients with any use of bDMARDs during the observational period were included in the bDMARD ever-user group, while those without bDMARD use were placed in the bDMARD nonuser group. The IR of malignancies was calculated in each group. The standardized incidence ratio (SIR) of DDMARD users was calculated based on bDMARD

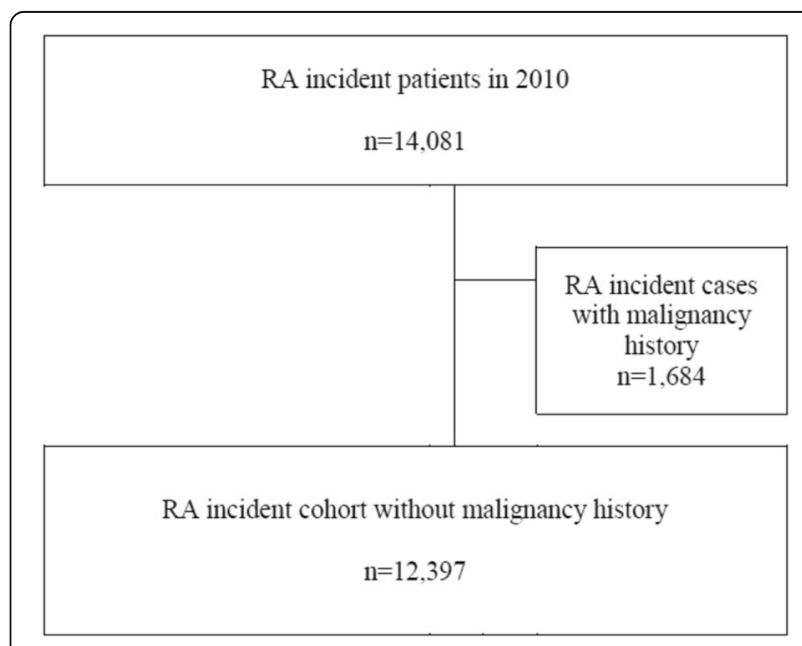

Fig. 1 Patient selection flow. RA rheumatoid arthritis 
nonusers. Nearly $95 \%$ of patients were bDMARD nonusers; therefore, the nonusers were considered the standard RA population.

\section{Nested case-control study}

A nested case-control study was performed on this inception cohort for early RA patients in order to evaluate the impact of bDMARDs on the development of malignancies. Patients were divided into two groups (patients with and without malignancies) according to the development of malignancies during the observation period of $>3$ years. Univariable and multivariable analyses were performed to identify the impact of bDMARD use on the development of all malignancies, and hematological malignancies specifically.

\section{Statistical analysis}

The crude IR of each malignancy (per 10,000 PY), and the respective $95 \%$ confidence intervals (CIs) were calculated. First, we compared the demographic and clinical characteristics between the bDMARD ever-user and nonuser groups using the chi-square test and the independent $t$ test. In order to estimate the relative risk of developing malignancies in bDMARD users compared to nonusers, we calculated the SIR (the number of observed malignancies per number of expected malignancies) after adjusting for age and sex. The 95\% CI was determined assuming that the frequency of observed cases followed a Poisson distribution.

In the case-control study, multivariable logistic regression models and Poisson regression models were used to identify the impact of bDMARD use on the development of overall and hematological malignancies. These models were performed after adjusting for the following parameters at baseline: age, sex, healthcare utilization (such as insurance type), type of institution, department type, number of comorbidities, and medication (including MTX, corticosteroids, and NSAIDs).

All analyses were performed using SAS 9.2 (SAS Institute, Cary, NC, USA). $p<0.05$ was considered statistically significant.

\section{Results}

\section{Baseline characteristics of the study population}

A total of 12,397 patients with early RA (41,599 PY) were included in analysis. The baseline characteristics of the study population are summarized in Table 1 . The mean patient age (standard deviation (SD)) was 52.7 (13.6) years and $76.8 \%$ of the patients were female. Hydroxychloroquine was the most frequently used DMARD (56.6\%), followed by methotrexate (MTX) at $42.6 \%$ and sulfasalazine at $21.8 \%$. In addition, $71.4 \%$ of the patients used corticosteroids and $91.7 \%$ used NSAIDs at baseline.
A total of 714 patients (5.8\%) had used bDMARDs. Only TNF inhibitors were allowed for use as a first-line bDMARD agent through December 2013 in South Korea. Therefore, all of the bDMARD users in this study were assumed to have been exposed to a TNF inhibitor. The bDMARD ever-user group was younger (mean age 47.5 vs 53.0 years, $p<0.01)$ and had a higher proportion of men $(36.1 \%$ vs $22.4 \%, p<0.01)$ than did the bDMARD nonuser group. There was no significant difference between the ever-user and nonuser group with regard to comorbidities. However, drug utilization varied considerably between the two groups. Both the prevalence of MTX use $(61.2 \%$ vs $41.5 \%, p<0.01)$ and its dosages $(10.9 \pm 3.1$ vs $9.7 \pm 3.0, p<0.01)$ were higher in bDMARD ever-users compared to those in bDMARD nonusers. Oral corticosteroids and NSAIDs were also more frequently used in the bDMARD user group than they were in the bDMARD nonuser group.

\section{Incidence of malignancy in early RA patients Incidence of malignancy in early $R A$ patients}

A total of 725 malignancies in 561 patients (200 in males and 361 in females) were diagnosed during the observation period. Among these, 140 patients had more than one malignancy. The total IR of overall malignancies in early RA patients was $174.3 / 10,000$ PY (95\% CI 161.6-187.0): 280.4/10,000 PY in men (95\% CI 246.7-314.1) and 142.9/10,000 PY (95\% CI 129.9156.0) in women.

The involved organ systems differed according to sex. In men $(n=2872,9486 \mathrm{PY})$, prostate malignancies were most common at 49.5/10,000 PY (95\% CI 35.4-63.7), followed by lung cancer $(34.8 / 10,000$ PY (95\% CI 22.946.7)), stomach cancer $(32.7 / 10,000$ PY (95\% CI $21.2-$ $44.2)$ ), and colorectal cancer $(29.5 / 10,000$ PY (95\% CI 18.6-40.4)). In women $(n=9525,32,113 \mathrm{PY})$, the IR of thyroid cancer was highest at 25.5/10,000 PY (95\% CI 20.0-31.1), followed by colorectal cancer $(17.4 / 10,000$ PY (95\% CI 12.9-22.0)), breast cancer (11.8/10,000 PY (95\% CI 8.1-15.6)), and pancreatic cancer $(11.5 / 10,000$ PY (95\% CI 7.8-15.2)) (Table 2).

\section{Incidence rate of malignancy in $W D M A R D$ users}

The IRs of malignancy according to the use of bDMARDs are presented in Table 3. In bDMARD users $(n=714,2454$ PY), the IR of overall malignancy was 81.5/10,000 PY (95\% CI 45.8-117.2). In contrast, the IR of overall malignancy in nonusers was $180.1 / 10,000$ PY (95\% CI 166.8-193.4). The SIR of overall malignancy in bDMARD users was only 0.5 (95\% CI $0.3-0.7$ ). However, for hematologic malignancy, the SIR in bDMARD users was 2.9 (95\% CI 0.4-10.5) for lymphoma and 3.2 (95\% CI 0.01-18.0) for leukemia, although these were not significant. 
Table 1 Baseline characteristics of early rheumatoid arthritis patients

\begin{tabular}{|c|c|c|c|c|}
\hline Variable & $\begin{array}{l}\text { Total } \\
(N=12,397)\end{array}$ & $\begin{array}{l}\text { bDMARD } \\
\text { ever-user } \\
(n=714)\end{array}$ & $\begin{array}{l}\text { bDMARD } \\
\text { nonuser } \\
(n=11,683)\end{array}$ & $p$ \\
\hline Age (years) & $52.7 \pm 13.6$ & $47.5 \pm 15.1$ & $53.0 \pm 13.4$ & $<0.01$ \\
\hline Female sex & $9525(76.8)$ & $456(63.9)$ & 9069 (77.6) & $<0.01$ \\
\hline Insurance type & & & & $<0.01$ \\
\hline Health insurance & $11,661(94.1)$ & $682(95.5)$ & $10,979(94.0)$ & \\
\hline Medicaid & $736(5.9)$ & $32(4.8)$ & $704(6.0)$ & \\
\hline Type of institution & & & & $<0.01$ \\
\hline Tertiary hospital & $2646(21.3)$ & $231(32.4)$ & $2415(20.7)$ & \\
\hline General hospital & $2430(19.6)$ & $161(22.6)$ & $2269(19.4)$ & \\
\hline Community hospitals/clinics/other & $7321(59.1)$ & $322(45.1)$ & $6999(59.9)$ & \\
\hline Department & & & & $<0.01$ \\
\hline Internal medicine & $5064(40.9)$ & $362(50.7)$ & $4702(40.3)$ & \\
\hline Orthopedic surgery & $5839(47.1)$ & $265(37.1)$ & $5574(47.7)$ & \\
\hline Other & $1494(12.1)$ & $87(12.2)$ & $1407(12.0)$ & \\
\hline Number of comorbidities & $0.84 \pm 1.01$ & $0.80 \pm 0.93$ & $0.85 \pm 1.01$ & 0.17 \\
\hline 0 & $5755(46.4)$ & $338(47.3)$ & $5417(46.4)$ & \\
\hline 1 & $3993(32.2)$ & $231(32.4)$ & $3762(32.2)$ & 0.76 \\
\hline$\geq 2$ & $2649(21.4)$ & $145(20.3)$ & $2504(21.4)$ & \\
\hline CCl score & $2.0 \pm 1.2$ & $1.9 \pm 1.1$ & $2.0 \pm 1.2$ & 0.14 \\
\hline Methotrexate use & $5283(42.6)$ & $437(61.2)$ & $4846(41.5)$ & $<0.01$ \\
\hline Methotrexate dose (mg/week) & $9.8 \pm 3.0$ & $10.9 \pm 3.1$ & $9.7 \pm 3.0$ & $<0.01$ \\
\hline Dosage $=0$ & $7114(57.5)$ & $277(38.8)$ & $6837(58.6)$ & \\
\hline $0<$ dosage $<10$ & $2452(19.8)$ & $147(20.6)$ & $2305(19.8)$ & $<0.01$ \\
\hline Dosage $\geq 10$ & $2814(22.7)$ & $290(40.6)$ & $2524(21.6)$ & \\
\hline Hydroxychloroquine & $7016(56.6)$ & $339(47.5)$ & $6677(57.2)$ & $<0.01$ \\
\hline Sulfasalazine & $2704(21.8)$ & $296(41.5)$ & $2408(20.6)$ & $<0.01$ \\
\hline Bucillamine & $737(5.9)$ & $31(4.3)$ & $706(6.0)$ & 0.07 \\
\hline Leflunomide & $687(5.5)$ & $84(11.8)$ & $603(5.2)$ & $<0.01$ \\
\hline Tacrolimus & $87(0.7)$ & $13(1.8)$ & $74(0.63)$ & $<0.01$ \\
\hline Oral corticosteroid use & $8851(71.4)$ & $549(76.9)$ & $8302(71.1)$ & $<0.01$ \\
\hline Corticosteroid dose (mg/day) & $7.4 \pm 4.8$ & $7.8 \pm 4.1$ & $7.4 \pm 4.8$ & 0.04 \\
\hline Dosage $=0$ & 3546 (33.3) & $165(26.0)$ & 3381 (33.7) & \\
\hline $0<$ dosage $<5$ & $1244(11.7)$ & $39(6.1)$ & 1205 (12.0) & $<0.01$ \\
\hline Dosage $\geq 5$ & $5874(55.1)$ & 431 (67.9) & $5443(54.3)$ & \\
\hline NSAID use & $11,366(91.7)$ & $671(94.0)$ & $10,695(91.5)$ & 0.03 \\
\hline
\end{tabular}

Data expressed as mean \pm standard deviation or number (percentage)

bDMARD biologic disease-modifying anti-rheumatic drug, $\mathrm{CCl}$ Charlson comorbidity index, NSAID nonsteroidal anti-inflammatory drug

Impact of malignancy on the development from $B D M A R D$ use The baseline characteristics of early RA patients according to the development of malignancies are summarized in Additional file 2: Table S2. In multivariable analysis adjusted for various factors, bDMARD use was associated with a low risk of malignancy (odds ratio (OR) 0.42 (95\% CI 0.25-0.73)), while older age (OR 1.04 (95\% CI 1.03-1.04)) and male (OR 1.88 (95\% CI 1.57-2.25)) increased the risk of malignancy development (Table 4). However, bDMARD use was not protective in the development of hematologic malignancies (OR 1.69 (95\% CI 0.38-7.59)) (Table 4).

\section{Discussion}

In this large population study, the IR of all malignancies in early RA patients was $174.3 / 10,000 \mathrm{PY}$, while that of 
Table $\mathbf{2}$ Incidence rates of malignancy in early rheumatoid arthritis patients by sex

\begin{tabular}{|c|c|c|c|c|c|c|}
\hline \multirow[t]{2}{*}{ Type of malignancy } & \multicolumn{2}{|c|}{$\begin{array}{l}\text { Total } \\
(N=12,397)\end{array}$} & \multicolumn{2}{|c|}{$\begin{array}{l}\text { Male } \\
(n=2872)\end{array}$} & \multicolumn{2}{|c|}{$\begin{array}{l}\text { Female } \\
(n=9525)\end{array}$} \\
\hline & $N$ & $\mathrm{IR}^{\mathrm{a}}(95 \% \mathrm{Cl})$ & N & $\mathrm{IR}^{\mathrm{a}}(95 \% \mathrm{Cl})$ & N & $\mathrm{IR}^{\mathrm{a}}(95 \% \mathrm{Cl})$ \\
\hline All malignancies & 725 & $174.3(161.6-187.0)$ & 266 & $280.4(246.7-314.1)$ & 459 & $142.9(129.9-156.0)$ \\
\hline Lip, oral cavity, and pharynx & 9 & $2.2(0.8-3.6)$ & 5 & $5.3(0.7-9.9)$ & 4 & $1.2(0.0-2.5)$ \\
\hline Esophagus & 3 & $0.7(0.1-1.5)$ & 3 & $3.2(0.4-6.7)$ & - & - \\
\hline Stomach & 61 & $14.7(11.0-18.3)$ & 31 & $32.7(21.2-44.2)$ & 30 & $9.3(6.0-12.7)$ \\
\hline Colon and rectum & 84 & $20.2(15.9-24.5)$ & 28 & $29.5(18.6-40.4)$ & 56 & $17.4(12.9-22.0)$ \\
\hline Liver & 52 & $12.5(9.1-15.9)$ & 22 & $23.2(13.5-32.9)$ & 30 & $9.3(6.0-12.7)$ \\
\hline Gallbladder & 10 & $2.4(0.9-3.9)$ & 2 & $2.1(0.8-5.0)$ & 8 & $2.5(0.8-4.2)$ \\
\hline Pancreas & 50 & $12.0(8.7-15.4)$ & 13 & $13.7(6.3-21.2)$ & 37 & 11.5(7.8-15.2) \\
\hline Larynx & 5 & $1.2(0.1-2.3)$ & 5 & $5.3(0.7-9.9)$ & - & - \\
\hline Lung & 60 & $14.4(10.8-18.1)$ & 33 & $34.8(22.9-46.7)$ & 27 & $8.4(5.2-11.6)$ \\
\hline Breast & 39 & $9.4(6.4-12.3)$ & 1 & $1.1(1.0-3.1)$ & 38 & $11.8(8.1-15.6)$ \\
\hline Cervix uteri & 17 & $4.1(2.1-6.0)$ & 0 & - & 17 & $5.3(2.8-7.8)$ \\
\hline Corpus uteri & 4 & $1.0(0.0-1.9)$ & 0 & - & 4 & $1.2(0.0-2.5)$ \\
\hline Ovary & 13 & $3.1(1.4-4.8)$ & 0 & - & 13 & $4.0(1.8-6.2)$ \\
\hline Prostate & 47 & $11.3(8.1-14.5)$ & 47 & $49.5(35.4-63.7)$ & 0 & - \\
\hline Testis & 3 & $0.7(0.09-1.5)$ & 3 & $3.2(0.4-6.7)$ & 0 & - \\
\hline Kidney & 8 & $1.9(0.6-3.3)$ & 4 & $4.2(0.1-8.3)$ & 4 & $1.2(0.0-2.5)$ \\
\hline Bladder & 14 & $3.4(1.6-5.1)$ & 8 & $8.4(2.6-14.3)$ & 6 & $1.9(0.4-3.4)$ \\
\hline Brain and CNS & 5 & $1.2(0.1-2.3)$ & 1 & $1.1(1.0-3.1)$ & 4 & $1.2(0.0-2.5)$ \\
\hline Thyroid & 87 & $20.9(16.5-25.3)$ & 5 & $5.3(0.7-9.9)$ & 82 & $25.5(20.0-31.1)$ \\
\hline Hematologic malignancy & 21 & $5(2.9-7.2)$ & 6 & $6.3(1.3-11.4)$ & 15 & $4.7(2.3-7.0)$ \\
\hline Hodgkin lymphoma & 1 & $0.2(0.2-0.7)$ & 0 & - & 1 & $0.3(0.3-0.9)$ \\
\hline Non-Hodgkin lymphoma & 13 & $3.1(1.4-4.8)$ & 4 & $4.2(0.1-8.3)$ & 9 & $2.8(1.0-4.6)$ \\
\hline Multiple myeloma & 1 & $0.2(0.2-0.7)$ & 0 & - & 1 & $0.3(0.3-0.9)$ \\
\hline Leukemia & 6 & $1.4(0.3-2.6)$ & 2 & $2.1(0.8-5.03)$ & 4 & $1.2(0.0-2.47)$ \\
\hline Others & 133 & $32.0(26.5-37.4)$ & 49 & $51.7(37.2-66.1)$ & 84 & $26.2(20.6-31.8)$ \\
\hline
\end{tabular}

IR incidence rate, $\mathrm{Cl}$ confidence interval, CNS central nervous system

${ }^{a}$ Incidence rate represents the incident cases per 10,000 person-years

hematologic malignancies was 5.0/10,000 PY. The risk of malignancy in bDMARD users was lower than that of nonusers, with the exception of hematologic malignancies.

The risk of malignancy in RA patients appears to vary widely among ethnicities and geographical regions with respect to genetic predisposition and environmental factors $[27,28]$. The IR of overall malignancy in this study is higher than that obtained in American studies using a national database (129.6/10,000 PY) [29]. In particular, the IR of overall malignancy in this study was much higher than that in Japan (67.5-82.0/10,000 PY) $[6,30]$ using registries. These differences are likely influenced by the different data sources. We used the national claims database, which does not have any loss to followup with regard to malignancy. Compared to the national database, a higher rate of loss to follow-up is the main cause of underestimation of severe outcomes in the disease-specific cohort study [31, 32]. One recent comparison study of five RA registries from several different countries based on considering different study designs found that the IRs for all malignancies, excluding skin cancers, were highly consistent across studies [33]. Use of the National Cancer Screening System is another important factor in the increased incidence of malignancies in our study compared to those in other studies. Interestingly, thyroid cancer was the most common type of malignancy in Korean patients with RA. This finding is quite different from that identified in other countries [2, 30, 34]. This trend for a high incidence of thyroid cancer has been seen in the general population in Korea [35]. South Korea has an aggressive screening system for the early detection of malignancies, including thyroid cancer. This screening program may contribute to the increased incidence of thyroid cancer detected in this study [36]. 
Table 3 Incidence rate of malignancies in early RA patients according to bDMARD use

\begin{tabular}{|c|c|c|c|c|c|}
\hline \multirow[t]{2}{*}{ Type of malignancy } & \multicolumn{2}{|c|}{$\begin{array}{l}\text { bDMARD ever-user } \\
(n=714)\end{array}$} & \multicolumn{2}{|c|}{$\begin{array}{l}\text { bDMARD nonuser } \\
(n=11,683)\end{array}$} & \multirow{2}{*}{$\begin{array}{l}\text { Standardized incidence rate } \\
\text { SIR }(95 \% \mathrm{Cl})^{\mathrm{b}}\end{array}$} \\
\hline & $\bar{N}$ & $\mathrm{IR}^{\mathrm{a}}(95 \% \mathrm{Cl})$ & N & $\mathrm{IR}^{\mathrm{a}}(95 \% \mathrm{Cl})$ & \\
\hline All malignancies & 20 & $81.5(45.8-117.2)$ & 705 & $180.1(166.8-193.4)$ & $0.5(0.3-0.7)$ \\
\hline Lip, oral cavity, and pharynx & 0 & - & 9 & $2.3(0.8-3.8)$ & - \\
\hline Esophagus & 0 & - & 3 & $0.8-(0.1-1.6)$ & - \\
\hline Stomach & 3 & $12.2(1.6-26.0)$ & 58 & $14.8(11.0-18.6)$ & $0.8(0.2-2.4)$ \\
\hline Colon and rectum & 1 & $4.07(3.9-12.0)$ & 83 & $21.2(16.6-25.8)$ & $0.2(0.0-1.1)$ \\
\hline Liver & 1 & $4.07(3.9-12.0)$ & 51 & $13.0(9.5-16.6)$ & $0.3(0.01-1.7)$ \\
\hline Gallbladder & - & - & 10 & $2.6(1.0-4.1)$ & - \\
\hline Pancreas & 1 & $4.07(3.9-12.0)$ & 49 & $12.5(9.0-16.0)$ & $0.3(0.01-1.8)$ \\
\hline Larynx & 0 & - & 5 & $1.3(0.2-2.4)$ & - \\
\hline Lung & 3 & $12.2(1.6-26.0)$ & 57 & $14.6(10.8-18.3)$ & $0.8(0.2-2.5)$ \\
\hline Breast & 3 & $12.2(1.6-26.0)$ & 36 & $9.2(6.2-12.2)$ & $1.3(0.3-3.9)$ \\
\hline Cervix uteri & 0 & - & 17 & $4.3(2.3-6.4)$ & - \\
\hline Corpus uteri & 0 & - & 4 & $1.0(0.0-2.0)$ & - \\
\hline Ovary & 0 & - & 13 & $3.3(1.5-5.1)$ & - \\
\hline Prostate & 0 & - & 47 & $12.0(8.6-15.4)$ & - \\
\hline Testis & 0 & - & 3 & $0.8(0.1-1.6)$ & - \\
\hline Kidney & 0 & - & 8 & $2.0(0.6-3.5)$ & - \\
\hline Bladder & 0 & - & 14 & $3.6(1.7-5.5)$ & - \\
\hline Brain and CNS & 0 & - & 5 & $1.3(0.2-2.4)$ & - \\
\hline Thyroid & 1 & $4.1(3.9-12.0)$ & 86 & $22.0(17.3-26.6)$ & $0.2(0.0-1.03)$ \\
\hline Hematologic malignancy & 3 & $12.2(1.6-26.0)$ & 18 & $4.6(2.5-6.7)$ & $2.7(0.6-7.8)$ \\
\hline Hodgkin lymphoma & 0 & - & 1 & $0.3(0.2-0.8)$ & - \\
\hline Non-Hodgkin lymphoma & 2 & $8.2(3.1-19.4)$ & 11 & $2.8(1.1-4.5)$ & $2.9(0.4-10.5)$ \\
\hline Multiple myeloma & 0 & - & 1 & $0.3(0.2-0.8)$ & - \\
\hline Leukemia & 1 & $4.1(3.9-12.0)$ & 5 & $1.3(0.2-2.4)$ & $3.2(0.1-18.0)$ \\
\hline Others & 4 & $16.3(0.3-32.3)$ & 129 & $33.0(27.3-38.6)$ & $0.5(0.1-1.3)$ \\
\hline
\end{tabular}

bDMARD biologic disease-modifying anti-rheumatic drug, $R A$ rheumatoid arthritis, $I R$ incidence rate, SIR standardized incidence rate, $C I$ confidence interval, $C N S$ central nervous system

Incidence rates represent incident cases per 10,000 person-years

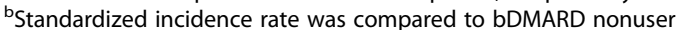

Table 4 Risk factors for the development of malignancy in early RA patients ${ }^{a}$

\begin{tabular}{|c|c|c|c|c|}
\hline \multirow[t]{3}{*}{ Variable } & \multicolumn{2}{|l|}{ Malignancies } & \multicolumn{2}{|c|}{ Hematologic malignancies } \\
\hline & Crude & Adjusted & Crude & Adjusted \\
\hline & OR $(95 \% \mathrm{Cl})$ & OR $(95 \% \mathrm{Cl})$ & OR $(95 \% \mathrm{Cl})$ & OR $(95 \% \mathrm{Cl})$ \\
\hline Age & $1.04(1.03-1.05)$ & $1.04(1.03-1.04)$ & $1.02(0.99-1.06)$ & $1.02(0.98-1.05)$ \\
\hline Male sex & $1.90(1.59-2.27)$ & $1.88(1.57-2.25)$ & $1.55(0.59-4.07)$ & $1.41(0.53-3.74)$ \\
\hline Comorbidities & $1.66(1.39-1.99)$ & $1.34(1.11-1.61)$ & $2.42(0.87-6.73)$ & $2.29(0.80-6.52)$ \\
\hline \multicolumn{5}{|l|}{ Medications } \\
\hline bDMARD ever use & $0.41(0.24-0.70)$ & $0.42(0.25-0.73)$ & $1.91(0.44-8.27)$ & $1.69(0.38-7.59)$ \\
\hline Methotrexate use & $0.90(0.76-1.07)$ & $0.93(0.78-1.12)$ & $1.21(0.49-2.97)$ & $1.06(0.41-2.74)$ \\
\hline Corticosteroid use & $1.03(0.86-1.25)$ & $1.05(0.86-1.28)$ & $1.12(0.40-3.11)$ & $1.02(0.35-2.95)$ \\
\hline NSAID use & $1.22(0.88-1.71)$ & $1.16(0.83-1.63)$ & $1.61(0.22-12.09)$ & $2.00(0.26-15.48)$ \\
\hline
\end{tabular}


The influence of bDMARDs on cancer development has been unclear $[11-18,20]$. Several recent reports have suggested that there is a lower IR of malignancy in TNF inhibitor users compared to that in bDMARD nonusers, or in the general population. The IR per 10,000 PY of malignancies was lower in TNF inhibitor users $(81 / 10,000$ PY) compared with bDMARD nonusers (117/10,000 PY) in the BSRBR [20], and was 53.5/10,000 PY in bDMARD users and 74.1/10,000 PY in bDMARD nonusers from the Taiwan national database [22]. The Japanese cohort for RA patients given bDMARDs (SECURE) recently also reported that the risk of overall malignancies was significantly lower in bDMARD users than it was in the general population [30]. Therefore, our finding of a beneficial effect of bDMARDs with regard to cancer development is consistent with these recent reports.

In our study, patients treated with bDMARDs were also more frequently exposed to MTX, corticosteroids, and NSAIDs (at higher dosages) than were nonusers of bDMARDs (Additional file 2: Table S2). Therefore, bDMARD users appear to have higher RA disease activity than do nonusers based on these medication requirements. Inflammation is believed to play a key role in the development of malignancy [4]. Treatment with bDMARDs, however, can potentially reduce this risk through appropriate activity control, reducing the need for other treatments in the long term.

However, our results also demonstrate that the risk of hematologic malignancies was unaffected by bDMARD use. In fact, the number of hematologic malignancies tended to be higher in bDMARD users compared to nonusers, although this was not statistically significant. Our study was limited to early RA patients with 3-4 years of follow-up. Therefore, the long-term effect of bDMARDs on the development of hematologic malignancies cannot be confirmed with this study. Further longterm observational studies are needed to clarify the risk of bDMARD use on the development of hematologic malignancies.

There is a well-recognized association between malignancy and RA itself. In this study, we included patients who were early in their RA disease course in order to control the disease duration and to avoid the influences of long-term exposure of conventional DMARDs on the incidence of malignancy. Our data did not show a meaningful difference in the IR of all malignancies in patients with early RA compared to that of established RA patients (reported in several registries). According to previous studies, early RA patients (SRR and NOAR) and established RA patients (CORRONA and IORRA) have similar incidences of malignancy [33].

Our study has several limitations. First, we did not adjust for the time of bDMARD use as a time-dependent variable. We decided not to use drug duration as a timedependent variable because of the relatively short length of our observational period. There has not been any evidence for a relationship between bDMARD exposure time and the risk of malignancy development based on many prior studies. Moreover, since our study showed that ever-exposure to bDMARDs was not a risk factor but a protective factor for the development of overall malignancies, we did not analyze bDMARD exposure as a time-dependent variable. Regardless, a longer study is needed to determine the long-term effects of bDMARD use in RA patients. A second limitation of this study is that we did not perform subgroup analysis according to the type of bDMARD. Some types of bDMARDs are noted to be risk factors for certain malignancies. However, we were unable to separate patients by specific bDMARD agents, because most of these patients were treated with TNF inhibitors, which are first-line bDMARDs according to our reimbursement guideline. Therefore, there may be few patients exposed to other bDMARDs in this study period. In addition, we could not adjust the clinical information, such as disease activity, because of the limitation of the claims database. However, we adjusted for the use of specific medications as surrogate markers of disease activity. We also adjusted comorbidities more accurately than was done in previous studies, in which adjustment was based on patients' reports or on the medical records of a single hospital. Finally, we could not compare the IR in the overall RA patients with that in the general population. A study matching population characteristics or observational periods will be needed for that.

This study also has several strengths. First, our study population was limited to patients who were early in the course of RA. Therefore, we could control for confounders such as disease duration and exposure time of various conventional DMARDs. Second, by excluding patients with a history of malignancy, we reduced the indication bias for bDMARD use. This strategy was meaningful when comparing the risks of malignancy development based on bDMARD use. A third strength of this study is that we used the National Claims Database, which covers the entire Korean population and therefore avoids selection bias. This large sample size and the availability of long-term records enhanced the statistical power to look at rare events and the accuracy of our study. In addition, this database prevents the underestimation of malignancy incidence and minimizes loss to follow up, while there is a risk of under-reporting of malignancies if patients leave the registry or are not adequately followed up in registry observational data. Furthermore, our data provide additional evidence leading to robust conclusions regarding the risk of malignancy in patients treated with bDMARDs because the pattern of concomitant DMARDs varies according to countries. 


\section{Conclusion}

The use of bDMARDs in early RA patients is associated with reduced risk of malignancy development, with the exception of hematological malignancies.

\section{Additional files}

Additional file 1: Table S1. Presenting diagnostic codes for malignancies. (DOCX $36 \mathrm{~kb}$ )

Additional file 2: Table S2. Presenting comparison of baseline characteristics between patients diagnosed with malignancies and patients without malignancies. (DOCX $19 \mathrm{~kb}$ )

\section{Abbreviations}

RA: Rheumatoid arthritis; bDMARD: Biologic disease-modifying anti-rheumatic drug; SIR: Standardized incidence ratio; PY: Person-years; DMARD: Diseasemodifying anti-rheumatic drug; MTX: Methotrexate; TNF: Tumor necrosis factor; HIRA: Health Insurance Review and Assessment; IR: Incidence rate; NSAID: Nonsteroidal anti-inflammatory drug; OR: Odds ratio

\section{Acknowledgements}

Not applicable.

\section{Funding}

This research was supported by a grant from the Korea Health Technology R\&D Project through the Korea Health Industry Development Institute (KHIDI), funded by the Ministry of Health \& Welfare, Republic of Korea (grant number: HI16C0061)

\section{Availability of data and materials}

All data generated or analyzed during this study are included in this published article.

\section{Authors' contributions}

S-KC and Y-KS contributed the study design, data analyses, interpretation of results, and writing of the manuscript. S-CB contributed the study design and interpretation of results. $\mathrm{MH}$ and $\mathrm{J}$ contributed data analyses and interpretation of results. All authors read and approved the final manuscript.

\section{Ethics approval and consent to participate}

The Health Insurance Review and Assessment (HIRA) Research Ethics Committee of South Korea approved this study protocol. Informed consent was not required because data were de-identified and collected retrospectively.

\section{Consent for publication}

Not applicable.

\section{Competing interests}

The authors declare that they have no competing interests.

\section{Publisher's Note}

Springer Nature remains neutral with regard to jurisdictional claims in published maps and institutional affiliations.

Received: 1 July 2017 Accepted: 20 November 2017

Published online: 15 December 2017

\section{References}

1. Abasolo L, Judez E, Descalzo MA, Gonzalez-Alvaro I, Jover JA, Carmona L, et al. Cancer in rheumatoid arthritis: occurrence, mortality, and associated factors in a South European population. Semin Arthritis Rheum. 2008;37(6):388-97.

2. Chen YJ, Chang YT, Wang CB, Wu CY. The risk of cancer in patients with rheumatoid arthritis: a nationwide cohort study in Taiwan. Arthritis Rheum. 2011;63(2):352-8.

3. Simon TA, Thompson A, Gandhi KK, Hochberg MC, Suissa S. Incidence of malignancy in adult patients with rheumatoid arthritis: a meta-analysis. Arthritis Res Ther. 2015;17:212.
4. Shacter E, Weitzman SA. Chronic inflammation and cancer. Oncology (Williston Park). 2002:16(2):217-26. 29; discussion 30-2.

5. Georgescu L, Quinn GC, Schwartzman S, Paget SA. Lymphoma in patients with rheumatoid arthritis: association with the disease state or methotrexate treatment. Semin Arthritis Rheum. 1997;26(6):794-804.

6. Hashimoto A, Chiba N, Tsuno H, Komiya A, Furukawa H, Matsui T, et al. Incidence of malignancy and the risk of lymphoma in Japanese patients with rheumatoid arthritis compared to the general population. J Rheumatol. 2015;42(4):564-71.

7. Kremer JM, Dougados M, Emery P, Durez P, Sibilia J, Shergy W, et al. Treatment of rheumatoid arthritis with the selective costimulation modulator abatacept: twelve-month results of a phase iib, double-blind, randomized, placebo-controlled trial. Arthritis Rheum. 2005;52(8):2263-71.

8. Lipsky PE, van der Heijde DM, St Clair EW, Furst DE, Breedveld FC, Kalden JR, et al. Infliximab and methotrexate in the treatment of rheumatoid arthritis. Anti-Tumor Necrosis Factor Trial in Rheumatoid Arthritis with Concomitant Therapy Study Group. N Engl J Med. 2000;343(22):1594-602.

9. Smolen JS, Aletaha D, Koeller M, Weisman MH, Emery P. New therapies for treatment of rheumatoid arthritis. Lancet. 2007;370(9602):1861-74.

10. Balkwill F. TNF-alpha in promotion and progression of cancer. Cancer Metastasis Rev. 2006;25(3):409-16.

11. Bongartz T, Sutton AJ, Sweeting MJ, Buchan I, Matteson EL, Montori V. AntiTNF antibody therapy in rheumatoid arthritis and the risk of serious infections and malignancies: systematic review and meta-analysis of rare harmful effects in randomized controlled trials. JAMA. 2006;295(19):2275-85.

12. Bongartz T, Warren FC, Mines D, Matteson EL, Abrams KR, Sutton AJ. Etanercept therapy in rheumatoid arthritis and the risk of malignancies: a systematic review and individual patient data meta-analysis of randomised controlled trials. Ann Rheum Dis. 2009;68(7):1177-83.

13. Askling J, Fahrbach K, Nordstrom B, Ross S, Schmid CH, Symmons D. Cancer risk with tumor necrosis factor alpha (TNF) inhibitors: meta-analysis of randomized controlled trials of adalimumab, etanercept, and infliximab using patient level data. Pharmacoepidemiol Drug Saf. 2011;20(2):119-30.

14. Leombruno JP, Einarson TR, Keystone EC. The safety of anti-tumour necrosis factor treatments in rheumatoid arthritis: meta and exposure-adjusted pooled analyses of serious adverse events. Ann Rheum Dis. 2009:68(7):1136-45.

15. Thompson AE, Rieder SW, Pope JE. Tumor necrosis factor therapy and the risk of serious infection and malignancy in patients with early rheumatoid arthritis: a meta-analysis of randomized controlled trials. Arthritis Rheum. 2011;63(6):1479-85.

16. Simon TA, Smitten AL, Franklin J, Askling J, Lacaille D, Wolfe F, et al. Malignancies in the rheumatoid arthritis abatacept clinical development programme: an epidemiological assessment. Ann Rheum Dis. 2009;68(12):1819-26.

17. Schiff MH, Kremer JM, Jahreis A, Vernon E, Isaacs JD, van Vollenhoven RF. Integrated safety in tocilizumab clinical trials. Arthritis Res Ther. 2011;13(5):R141.

18. Lopez-Olivo MA, Tayar JH, Martinez-Lopez JA, Pollono EN, Cueto JP, GonzalesCrespo MR, et al. Risk of malignancies in patients with rheumatoid arthritis treated with biologic therapy: a meta-analysis. JAMA. 2012;308(9):898-908.

19. Yamamoto K, Goto H, Hirao K, Nakajima A, Origasa H, Tanaka K, et al. Longterm safety of tocilizumab: results from 3 years of followup postmarketing surveillance of 5573 patients with rheumatoid arthritis in Japan. J Rheumatol. 2015;42(8):1368-75.

20. Mercer LK, Lunt M, Low AL, Dixon WG, Watson KD, Symmons DP, et al. Risk of solid cancer in patients exposed to anti-tumour necrosis factor therapy: results from the British Society for Rheumatology Biologics Register for Rheumatoid Arthritis. Ann Rheum Dis. 2015;74(6):1087-93.

21. Lan JL, Tseng CH, Chen JH, Cheng CF, Liang WM, Tsay GJ. Reduced risk of all-cancer and solid cancer in Taiwanese patients with rheumatoid arthritis treated with etanercept, a TNF-alpha inhibitor. Medicine (Baltimore). 2017; 96(7):e6055.

22. Wu CY, Chen DY, Shen $J$, Ho HJ, Chen CC, Kuo KN, et al. The risk of cancer in patients with rheumatoid arthritis taking tumor necrosis factor antagonists: a nationwide cohort study. Arthritis Res Ther. 2014;16(5):449.

23. Keystone EC. Does anti-tumor necrosis factor-alpha therapy affect risk of serious infection and cancer in patients with rheumatoid arthritis?: a review of longterm data. J Rheumatol. 2011;38(8):1552-62.

24. Song YJ. The South Korean Health Care System. Japan Med Assoc J. 2009; 52(3):206-9.

25. Cho SK, Sung YK, Choi CB, Kwon JM, Lee EK, Bae SC. Development of an algorithm for identifying rheumatoid arthritis in the Korean National Health Insurance claims database. Rheumatol Int. 2013;33(12):2985-92. 
26. Seo HJ, Oh HH, Yoon SJ. A comparison of the cancer incidence rates between the national cancer registry and insurance claims data in Korea Asian Pac J Cancer Prev. 2012;13(12):6163-8.

27. Centers for Disease C, Prevention. Racial/ethnic disparities and geographic differences in lung cancer incidence-38 States and the District of Columbia, 1998-2006. MMWR Morb Mortal Wkly Rep. 2010;59(44):1434-8.

28. Haselkorn T, Whittemore AS, Lilienfeld DE. Incidence of small bowel cancer in the United States and worldwide: geographic, temporal, and racial differences. Cancer Causes Control. 2005;16(7):781-7.

29. Wolfe F, Michaud K. Biologic treatment of rheumatoid arthritis and the risk of malignancy: analyses from a large US observational study. Arthritis Rheum. 2007;56(9):2886-95.

30. Harigai M, Nanki T, Koike R, Tanaka M, Watanabe-Imai K, Komano Y, et al. Risk for malignancy in rheumatoid arthritis patients treated with biological disease-modifying antirheumatic drugs compared to the general population: a nationwide cohort study in Japan. Mod Rheumatol. 2016; 26(5):642-50.

31. Ferrie JE, Kivimaki M, Singh-Manoux A, Shortt A, Martikainen P, Head J, et al. Non-response to baseline, non-response to follow-up and mortality in the Whitehall II cohort. Int J Epidemiol. 2009;38(3):831-7.

32. Greene N, Greenland S, Olsen J, Nohr EA. Estimating bias from loss to followup in the Danish National Birth Cohort. Epidemiology. 2011;22(6):815-22.

33. Askling J, Berglind N, Franzen S, Frisell T, Garwood C, Greenberg JD, et al. How comparable are rates of malignancies in patients with rheumatoid arthritis across the world? A comparison of cancer rates, and means to optimise their comparability, in five RA registries. Ann Rheum Dis. 2016; 75(10):1789-96.

34. Carmona L, Abasolo L, Descalzo MA, Perez-Zafrilla B, Sellas A, de Abajo F, et al. Cancer in patients with rheumatic diseases exposed to TNF antagonists. Semin Arthritis Rheum. 2011;41(1):71-80.

35. Oh CM, Won YJ, Jung KW, Kong HJ, Cho H, Lee JK, et al. Cancer statistics in Korea: incidence, mortality, survival, and prevalence in 2013. Cancer Res Treat. 2016:48(2):436-50.

36. Ahn HS, Kim HJ, Welch HG. Korea's thyroid-cancer "epidemic" - screening and overdiagnosis. N Engl J Med. 2014;371(19):1765-7.

\section{Submit your next manuscript to BioMed Central and we will help you at every step:}

- We accept pre-submission inquiries

- Our selector tool helps you to find the most relevant journal

- We provide round the clock customer support

- Convenient online submission

- Thorough peer review

- Inclusion in PubMed and all major indexing services

- Maximum visibility for your research

Submit your manuscript at www biomedcentral.com/submit

Biomed Central 